\title{
What Brings the Innovation in Business Model(s)? Evidence from Pakistan Mobile Banking Sector
}

\author{
Malkah Noor Kiani * $\quad$ Syed Hussain Mustafa Gillani ${ }^{\dagger}$
}

\begin{abstract}
Establishment of a new form of business model(s) by carrying many B2B partnerships among banks, cellular companies and government institutions, etc. serves the necessity for the survival in complex dynamics of newly emerged Pakistani mobile-banking sector. This study intends to examine the elements that influence extent of innovation in formation of new business model(s) among this newly emerged service sector. Four research questions have been developed. The questionnaire has been filled by 345 top executives and middle managers chosen through stratified sampling strategy. The gathered data was analyzed using the regression-based conditional process analysis (Hayes, 2017). The findings revealed some vital pieces of information for both practitioners and academicians. The significance of work is justified with the fact that this study effort to address some of the research gaps of existing literature body.
\end{abstract}

Keywords: Innovation capabilities, knowledge exploration, knowledge exploitation, service innovation success, contextual ambidexterity, business model innovation.

\section{Introduction}

The establishment of SBP branch less banking regulations of Pakistan have led to the emergence of one of the newly service sectors that is mobile banking sector. This paved the way for many public-private partnerships among banks, cellular companies, government institutions, etc. that have formed a national good governance ecosystem with an objective to facilitate the government in advancement towards digitization. Service recipients of these B2B arrangements are benefited with improved, secure and better services that could not be guaranteed by traditional mechanisms of past.

Banks, cellular companies, cash-rich business units (i.e. grocery stores, petrol stations, etc.) and other government institutions in Pakistani mobile banking sector are viewing the financial transactions as a new business opportunity. It has paved the way for new modes of service provision by these market players to general public with ease and convenience in Pakistan (PTA, 2018). The Government of Pakistan (Pakistan Telecommunication Authority and State Bank of Pakistan) have legalized these B2B partnerships by introducing a 'Third Party Service Provider model' (PTA, 2017). These legal statutory has allowed

\footnotetext{
*Visiting Lecturer, School of Management Studies, The University of Faisalabad, Pakistan.

E-mail address: 1431178@szabist-isb.pk.

$\dagger$ Additional Director QEC and Assistant Professor, School of Management Studies, The University of

Faisalabad, Pakistan.
} 
the private entities to roll out new business models and collaborative ventures to provide ease to general public in different private financial transactions and payment mechanisms. Consequent to these recent digitizations, launch of new technology-based applications and new types of business model have contributed to overall growth of this newly emerged service sector of Pakistan (PTA, 2018). This also further highlights the importance of concept business model innovation especially in this newly developing digital service-sectors of Pakistan that is mobile banking industry. It is important to state here that review of extensive literature also discloses that the existing researches on business model innovation have adopted the qualitative research method and limited or least researches is available with empirical testing of the operationalization. This also indicates a gap in literature body. Geissdoerfer, Vladimirova, Fossen, and Evans (2017) also debated that future researches necessarily needs to validate the dimensions of business model innovation through empirical analysis in different cultural contexts. Saebi, Lien, and Foss (2017) also argued that more cross-cultural empirical researches are needed to validate this construct in different cultural contexts. There is a need for future researches to bring coherence and legalize the components that constitute the business model innovation through empirical analysis (Bashir \& Verma, 2019). Thus, it can be stated that studying and validating the measures of business model innovation is of prime importance and attempts to fill this identified research gap in the existing body of knowledge.

Further review of the extensive literature body has disclosed that there exist some research gaps in the realm of business model innovation. The review of the literature reveals that this construct is the newly evolved (Spieth, Schneckenberg, \& Ricart, 2014). The literature on the construct business model innovation have failed in achieving the consensus and general belief that what are the elements that constitute the business model innovation (Foss \& Saebi, 2018; Saebi et al., 2017; Trapp, Voigt, \& Brem, 2018). The existing researches are also not harmonized. There exists incoherency in the determinants of business model innovation among researchers in various different directions. This issue of incoherence among the studies may be obvious because this construct is the newly evolved and presentation of different aspects, viewpoints and debates serve as the foundation for the knowledge building mechanism (Spieth et al., 2014). Resultantly, this may not be fruitful for the general agreement on operationalization of concept over the newly emerging concept. This has created a gap in existing knowledge body as well as the managers to understand the mechanism of business model innovation in the real world. The understanding of what constitutes and contributes to the business model innovation is something essential for the managers or practitioners to be familiar with. Some of the researches have presented their viewpoints on the elements or constituents of business model innovation, but limited empirical evidence of these viewpoints further doubts the generalizability of their statement (Foss \& Saebi, 2018). A very little is also known on the matter from where this business model innovation originates or instigates in the organization (Hossain, 2017; Geissdoerfer et al., 2017). This highlights that the problems exist in the existing literature of this construct.

It is also important to state that the researches on antecedents of business model innovation are most neglected in present research streams and thus, further paves the way for the future scholarly researches (Schneider \& Spieth, 2013; Foss \& Saebi, 2018). There 
arises a need to further explore the elements that serves as precursor to this construct. This serves as a research gap. In addition, Teece (2018) argued that there is a need to examine the influence of innovation capabilities on some outcome related performance indicators i.e. service innovation success in addition to this construct. This is also identified as a research gap in existing literature body.

It has also been found from the review of literature that the different researchers have conducted detailed research on the concept of innovation capabilities in varying perspectives (Kiani, Mustafa, \& Ahmad, 2019; Kiani, Ahmad, \& Gillani, 2019). Despite the existence of researches relating innovation capabilities, still there is a need to further validate this construct. The existing body of knowledge does not pertain the general consensus on the particular definition of innovation capabilities. This is particularly important when there is no agreement in the existing literature on those factors that determine the innovation capabilities for the attainment and assurance of service innovation success (Zawislak, Cherubini Alves, Tello-Gamarra, Barbieux, \& Reichert, 2012). This establishes the need to empirically validate the determinants of innovation capabilities with an objective to generate foci of vast conceptualization in a specific direction for the overall uniformity (Narcizo, Canen, \& Tammela, 2017). This also serves as a research gap. It is pertinent to mention here that that the economies of western counterparts are different than the developing economies in their institution, infrastructural and economic structures (Hofstede, 2001). The researches on these constructs conducted in the West need to be reconsidered, validated and tested for further modification, alteration, and extension of theories/conception among the developing countries.

Thus, the guiding problem statement of this study is, "there is a need to empirically testify the nature of the influence of innovation capabilities, knowledge exploration, knowledge exploitation, contextual ambidexterity, service innovation success on the business model innovation among the cultural context of mobile banking sector of Pakistan".

\section{Literature Review}

\section{Theoretical Perspective}

The theoretical foundations of this study revolve around the dynamic capabilities perspective and organizational learning theory. The dynamic capabilities perspective stresses on renewing the existing capabilities of the organization along with the generation of new innovative capabilities in order to achieve the overall business success and sustainability. However, in order to ensure sustainability, the adaptive processes of ambidexterity are equally important for the organization in parallel with the capabilities of exploring the new opportunities (Peng, Zhang, Yen, \& Yang, 2019). The organizational learning theory research also claims that the mechanism of knowledge exploration helps the organization in creating new form of knowledge (in addition to existing knowledge). And this theory further assumes that the exploitation of knowledge further improvises the utilization of capabilities (Yamakawa, Yang, \& Lin, 2011). Exploration emphasizes the organization's urge to search for growth opportunities while the exploitation may be termed as form of dynamic capability by some researchers that reflect the organization urged to develop 
its existing markets by expanding to new markets (Peng et al., 2019). This reflects that successful exploration, as well as exploitation, may be a necessary prerequisite for sustainable innovation in business models. Kim, Lim, and Yoo (2019) argued that despite the researcher's consensus on the importance of these two forms of learnings but still the existing literature pertains the limited empirical evidence on the role of explorative and exploitative learnings in relation with the innovation and ambidexterity between these two learning practices.

\section{Hypotheses Development}

Survival in the tough market dynamics may only be ensured if the organization continuously strives to meet the growing customer needs (Teece, 2012). However, it raises the question that continuous attempt to meet the customer needs further entails the organization to strengthen its core capabilities to innovate. The innovation capabilities are a blend of various abilities that may involve sensing the potential opportunities from market to implementing the perceived opportunity into real-facet. This may indicate that the organization may not essentially require to carry all the different capabilities in strengthen manner. Teece (2018) has also argued that an organization may good in sensing the growing market opportunities but, on the other hand, may not be strong enough to scale those new market opportunities into existing business processes. Thus, it may not be wrong to state that the overall strength of innovation capabilities of an organization lies at the extent of the value it captures for itself and delivers for customer. This fact is also indicated by many other researchers that debated that innovation capabilities are truly reflected in the extent of value capture and value deliver by the organization (Bashir \& Verma, 2019). This also indicates the persuasion of continuous innovation by the organization in development of new business model(s). Teece (2018) also argued that innovation capabilities may carry some influential effects on the business model innovation that needs to be empirically investigated. Thus, in light of this argument, the hypothesis one is established as;

\section{$H_{1}$ : Innovation capabilities may carry an impact on business model innovation.}

The review of the existing literature body revealed that the innovation capabilities serve as a antecedent to the service innovation success (Janssen, Castaldi, \& Alexiev, 2016). It is also obvious that an organization carrying stronger innovative capabilities may obviously experience greater success in newly offered/produced services or product. However, it is also indicated by literature that there is a need to study the innovation capabilities and the concept of business model innovation in lieu of some performance indicators that could be success of service innovation. It is essential to explain here that the stronger the innovation capabilities may yield more success in newly offered services, consequently this would enable the organization to carry the innovation in its business model by breaking its static nature (Kiani, Mustafa, \& Ahmad, 2019). The dynamic and changing market needs of the industry requires the organization to break the static shells of their traditional business model in order to offer more customized and value service delivery, in addition, to capture and proposition of value for itself. Thus, it indicates that 
the success of newly innovated services may facilitate the organization in transforming its innovation capabilities into established new forms of business models. Teece (2018) also argued that the role of some performance indicator i.e. success of service innovation etc. in connection with the innovation capabilities may need to examine that also serves as a research gap in literature. The recent researches on service innovation also indicated that the success of service innovation may vary among different service sectors and thus, can be termed as homogenous for all the service sectors (Ostrom et al., 2010). It has also been discussed in literature that the concept of service innovation success may vary among different cultural contexts and there is a need to conduct more empirical studies to generate the generalizability on the validation of this construct.

Taken all above, this study argues that stronger the innovation capabilities of the organization may yield a higher ratio of service innovation success that would further, in turn, positively affects the extent of innovation in business model. Thus, hypothesis two is established as;

$\mathrm{H}_{2}$ : Success of service innovation may carry the mediation influence among the innovation capabilities and business model innovation relationship.

Another research gap in the existing literature is the limited empirical researches on the relationship of two learning capabilities of knowledge exploration practices and knowledge exploitation practices in connection with the contextual ambidexterity. In light of this identified research gap, this study proposes that an organization carries two distinct capabilities that are knowledge exploration and knowledge exploitation. When an organization engages itself in searching for new knowledge and then engages itself in utilization of this acquired knowledge, basically helps herself in improving the efficiency of business processes (Li \& Huang, 2012; Laursen \& Salter, 2006). However, the extent and nature of knowledge exploration and exploitative practices may carry the interaction effect with the innovation capabilities of the organization. This means that although the strong innovation capabilities may yield the higher success ratio of service innovation but the absence or lower knowledge exploration and exploitative practices may subvert or undermine the positive effects of innovation capabilities to produce the success in service innovation. Thus, hypothesis three and four are established as;

$H_{3}$ : Knowledge exploration and knowledge exploitative may carry a moderating effect on innovation capabilities and success of service innovation relationship.

Gibson and Birkinshaw (2004) argued that knowledge exploration and knowledge exploitative practices are more favorable to the organization when this knowledge is aligned and adaptable by the organizational members in pursuit of organizational goals. The literature claims that Toyota is an example that carried the knowledge exploration and knowledge exploitative practices for more than decade. Knowledge exploration and exploitative may be more effective when an organization pursues the adoption of both a continuous mechanism. The effectiveness of knowledge exploration and exploitation may become condition on the internal environment of the organization that may allow each and 
every organizational member to wholeheartedly participate and putt effort into cultivating the value-creating ideas. Thus, it indicates that the alignment and adaptability of the explored and exploited knowledge is something essential to achieve the success of new value offering services (Kang \& Snell, 2009). Hughes (2018) conducted detailed bibliographic literature-based research on organizational ambidexterity and argued that very limited research has been carried up till now on the contextual ambidexterity to draw some valued outcome that is also identified as a research gap (Peng et al., 2019). Taken all above, this study proposes that contextual ambidexterity may carry an interaction effect with the innovation capabilities as well as the knowledge exploration and exploitative practices and may carry a moderation influence on the association of innovation capabilities with the success of service innovation. Thus, hypothesis five is established as;

$H_{4}$ : Contextual ambidexterity may carry a moderating effect on innovation capabilities and success of service innovation relationship.

Figure 1

Proposed Research Model of this Study

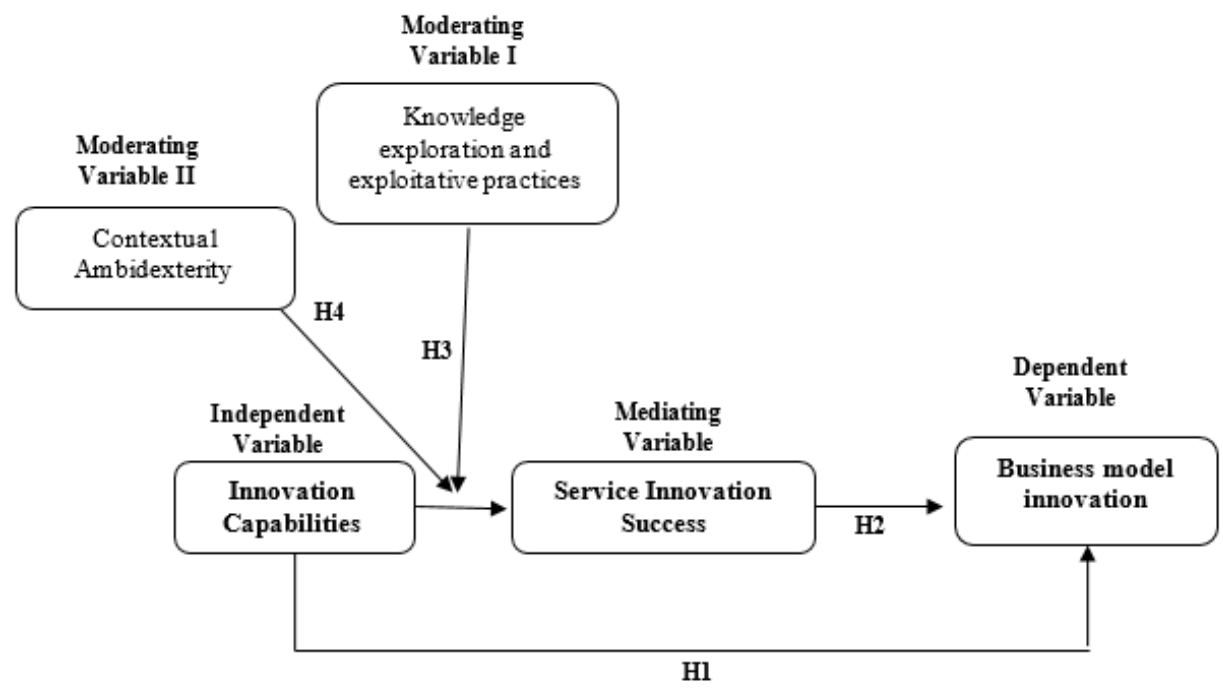

This study attempt to answer the identified research gaps by empirically testing the above four research hypotheses. This consequently has led to the formation of proposed model of study. It is essential to state that the presently very limited empirical researches on the antecedents of business model innovation are available that is also identified as a gap (Foss \& Saebi, 2018). Empirical testing of the research model can be made by the establishment of hypothesis six as;

H5: Innovation capabilities may carry a positive effect on business model innovation via the mediation influence of service innovation success that is moderated by knowledge 
exploration, knowledge exploitation, and contextual ambidexterity.

\section{Methodology}

\section{Research Measures}

This study comprises six important research constructs that include, (i) innovation capabilities, (ii) service innovation success, (iii) knowledge exploration practices, (iv) knowledge exploitation practices, (v) contextual ambidexterity and (vii) business model innovation. The research measure innovation capabilities is operationalized into five sub-constructs and measured with the fifteen items scale adopted from the existing work of Hertog (2000). These five sub-constructs are sensing user needs, sensing technological options, coproducing and orchestring, conceptualizing, scaling and stretching. The research measure service innovation success is measured with 13-item scale adopted from the existing research. The research measure knowledge exploitation practices are uni-dimensional measure and are measured with two-item scale adopted from work of Gonzalez and de Melo (2018). Knowledge exploration refers to discovery, experimentation and a search for new knowledge with the objective of improving and developing the existing product, services or processes. Knowledge exploitation, on the other hand refers to the utilization of the same knowledge with the core objective of bringing incremental changes for the overall efficiency and development of processes. The knowledge exploitation is measured with the two items adopted from the work of Gonzalez and de Melo (2018). Contextual ambidexterity is operationalized into two sub-constructs as perceived alignment and perceived adaptability. The contextual ambidexterity is measured with the six-item scale adopted from the previous work of Gibson and Birkinshaw (2004). The research measure business model innovation is operationalized into three sub-constructs and is measured with the thirty-three items scale adopted from the work of Clauss (2017). These three sub-constructs are value creation, value proposition and value capture innovation. The appendix illustrates the cumulative seventy-four measure items used for this research study.

\section{Population, Sample and Data Collection}

The population of this study comprises of mobile banking sector of Pakistan. It is important to state that this service sector is one of the newly evolved Pakistani sector that is expected to further evolve as the foundation-pillar of the country's economy in forthcoming years (PTA, 2018). Presently, the mobile banking sector of Pakistan comprises of only five financial payment mechanisms that include, Easypaisa, Mobicash, UBL Omni, Timepey and Upayment. These five financial payment mechanisms are operated by four different cellular companies in joint ventures with eight different financial institutes namely, Tameer microfinance bank, Waseela microfinance bank, United bank limited, Askari bank, Habib bank limited, Summit bank limited, Soneri Bank and Bank Al Habib Limited. Top and middle management including chief officers, chief executives, departmental heads, zonal heads, general managers, deputy general managers, and senior managers were selected as 
unit of analysis. They are chosen for unit of analysis because some of the researches indicated that the research measures of innovation capabilities, knowledge service innovation success and business model innovation are best reflected among the key position holders of middle and top management (Clauss, 2017). Thus, the total population of this study consists of 2736 participants as provided by details from respective HR departments of the cellular companies and banks. In order to ensure the generalizability of the results, the required sample size for 2736 population is calculated as 337, using the Krejcie and Morgan (1970) explanation of sample size estimation. This study has adopted the stratified sampling strategy for selection of sample. Using the proportionate stratified sampling strategy, 500 questionnaires were floated and 345 completely filled questionnaires were received back with the cumulative response rate of 69.0 percent.

\section{Data Analysis}

\section{Participant's Demographic Characteristics}

The results showed that 33.69 percent of respondents (117) were female and the 66.31 percent were males (242). The results also showed 19.50 percent of respondents (71) belong to the ages of 20 years to 30 years, 68.57 percent belongs to the ages of 31 years to 40 years and the 13.93 percent ( 51 respondents) are of the ages above than 40 years as also shown in table 1.

Table 1

Participants Demographic Attributes

\begin{tabular}{llcc}
\hline Demographics & Categories & Frequency & Percent \\
\hline \multirow{3}{*}{ Gender } & Female & 117 & 33.91 \\
& Male & 228 & 66.09 \\
& Total & 345 & 100 \\
& $20-30$ yrs & 67 & 19.42 \\
& $31-40 y r$ & 231 & 66.96 \\
\multirow{5}{*}{ Education } & Above 40 yrs & 47 & 13.62 \\
& Total & 345 & 100 \\
& Bachelor & 10 & 2.9 \\
& Masters & 276 & 80 \\
& MS/MPhil/PhD & 59 & 17.1 \\
& Total & 345 & 100 \\
\hline
\end{tabular}

\section{Validity Analysis, Composite Reliability and Average Variance}

\section{Extracted}

The convergent validity and discriminate validity of all the research measures were checked by using the principal component analysis (varimax rotation), confirmatory factor analysis and Pearson correlation. Table 2 illustrates the result of principal component analysis and the Cronbach alpha values of research measures. The results revealed that the loadings of all the research measures (except five items) carry the value above 0.6 that is acceptable. These five items (i.e. 19, 23, 36, 55 and 59) with lower factor loadings (i.e. below 0.6) were 
omitted from research instrument in further analysis. Thus, these results of convergent validity are considered as acceptable.

The reliability of the research constructs was checked through Cronbach's alpha values illustrated in table 2. All the Cronbach alpha values are also found satisfactory that is above 0.6. The discriminate validity of instrument was also checked by correlation values among the sub constructs as depicted in table 3 . The results revealed that the correlation among all the sub-constructs of the study variables is weak or negligible that also reflects their distinguishable attribute among sub-constructs.

\section{Hypotheses Testing}

The hypothesis one was empirically testing through simple regression analysis. The results are shown in table 1 which depicts that the innovation capabilities possess the significant positive effect of coefficient beta value $=.473$ with $\mathrm{p}$-value $=.000$ (that is less than .05 ) Thus, it proves the hypothesis one as valid.

The remaining hypotheses 2-5 were tested by using regression based conditional process analysis (Hayes, 2017). The results are revealed at table no 6. It was found that 71.37 percent of variance on business model innovation can be explained by this dual moderated mediation proposed research model with the F-value of 49.02 and p-value of .000 (that is less than .05). The results also showed that service innovation success possess the positive mediation effect of coefficient value .4736 with the p-value .091 that is less than .05 (this confirms the existence of mediation influence between innovation capabilities and business model). Thus, the hypothesis two is found to be acceptable.

Table 5 also reflects that the knowledge exploration and exploitative practices carries a positive moderation effect of coefficient value .3016 , $\mathrm{p}$-value $=.000<.05$ and $\mathrm{t}$-value $9.68>2$. This moderation effect of knowledge exploration and exploitative practices casts the additional positive interaction effect of .1998 with the p-value of $.000<.05$ on the service innovation success. Thus, it also confirms the hypothesis three as true. The results also reflects that the contextual ambidexterity also possess the positive moderation effect of coefficient value $.2718, \mathrm{p}$-value $=.000<.05$ and t-value $8.34>2$. This moderation effect of contextual ambidexterity casts the additional positive interaction effect of .2031 with the p-value of $.000<.05$ on the service innovation success. Thus, it also confirms the hypothesis four as accepted. In addition, the results also reflects that the innovation capabilities carries the positive indirect effect on the business model innovation via the positive mediation effect of service innovation success (of coefficient value .2741) that is positively moderated by knowledge exploration, and exploitative practices, (of coefficient value .3016) and contextual ambidexterity (of coefficient value .2718) along with two different forms of interaction effect - one (Innovation capabilities x knowledge exploration exploitative practices $=.1998$ ) and interaction effect two (Innovation capabilities $\mathrm{x}$ contextual ambidexterity $=.2031$ ). Thus, it proves the hypothesis five as true. 
Table 2

Results of convergent validity and reliability analysis

\begin{tabular}{|c|c|c|c|c|c|}
\hline Construct & Sub-Constructs & Item & $\begin{array}{c}\text { Factor } \\
\text { Loadings }\end{array}$ & $\begin{array}{c}\text { Reliability after } \\
\text { extraction }\end{array}$ & AVE \\
\hline \multirow[t]{16}{*}{ Innovation capabilities } & \multirow[t]{3}{*}{ Sensing user needs } & 1 & 0.955 & \multirow[t]{3}{*}{0.945} & \multirow[t]{3}{*}{0.897} \\
\hline & & 2 & 0.938 & & \\
\hline & & 3 & 0.949 & & \\
\hline & \multirow[t]{3}{*}{ Sensing technological options } & 4 & 0.902 & \multirow[t]{3}{*}{0.837} & \multirow[t]{3}{*}{0.744} \\
\hline & & 5 & 0.840 & & \\
\hline & & 6 & 0.844 & & \\
\hline & \multirow[t]{3}{*}{ Conceptualization } & 7 & 0.859 & \multirow[t]{3}{*}{0.796} & \multirow[t]{3}{*}{0.677} \\
\hline & & 8 & 0.852 & & \\
\hline & & 9 & 0.754 & & \\
\hline & \multirow[t]{3}{*}{ Coproducing and Orchestring } & 10 & 0.875 & \multirow[t]{3}{*}{0.943} & \multirow[t]{3}{*}{0.876} \\
\hline & & 11 & 0.966 & & \\
\hline & & 12 & 0.964 & & \\
\hline & \multirow[t]{3}{*}{ Scaling and stretching } & 13 & 0.863 & \multirow[t]{3}{*}{0.704} & \multirow[t]{3}{*}{0.676} \\
\hline & & 14 & 0.869 & & \\
\hline & & 15 & 0.727 & & \\
\hline & Total & 15 & - & 0.706 & 0.774 \\
\hline \multirow[t]{12}{*}{ Service Innovation Success } & \multirow{4}{*}{ Short term success } & 16 & 0.963 & \multirow[t]{4}{*}{0.904} & 0.855 \\
\hline & & 17 & 0.930 & & \\
\hline & & 18 & 0.879 & & \\
\hline & & 19 & 0.203 & & \\
\hline & Long term success & 20 & 0.953 & 0.901 & 0.833 \\
\hline & & 21 & 0.835 & & \\
\hline & & 22 & 0.946 & & \\
\hline & & 23 & 0.066 & & \\
\hline & Indirect success & 24 & 0.806 & 0.928 & 0.799 \\
\hline & & 25 & 0.933 & & \\
\hline & & 26 & 0.936 & & \\
\hline & Total & 11 & - & 0.790 & 0.829 \\
\hline Business Model Innovation & New capabilities & 27 & 0.880 & 0.937 & 0.837 \\
\hline & & 28 & 0.934 & & \\
\hline & & 29 & 0.930 & & \\
\hline & New technology & 30 & 0.914 & 0.957 & 0.822 \\
\hline & & 31 & 0.923 & & \\
\hline & & 32 & 0.882 & & \\
\hline & New partnerships & 33 & 0.916 & 0.883 & 0.803 \\
\hline & & 34 & 0.862 & & \\
\hline & & 35 & 0.909 & & \\
\hline & & 36 & 0.048 & & \\
\hline & New processes & 37 & 0.781 & 0.893 & 0.812 \\
\hline & & 38 & 0.956 & & \\
\hline & & 39 & 0.955 & & \\
\hline & New offerings & 40 & 0.949 & 0.945 & 0.884 \\
\hline & & 41 & 0.936 & & \\
\hline & & 42 & 0.936 & & \\
\hline & New customers and markets & 43 & 0.889 & 0.896 & 0.770 \\
\hline & & 44 & 0.859 & & \\
\hline & & 45 & 0.885 & & \\
\hline & New channels & 46 & 0.828 & 0.869 & 0.719 \\
\hline & & 47 & 0.852 & & \\
\hline & & 48 & 0.864 & & \\
\hline & New customer relationships & 49 & 0.938 & 0.946 & 0.874 \\
\hline & & 50 & 0.925 & & \\
\hline & & 51 & 0.942 & & \\
\hline
\end{tabular}


Table 2

\begin{tabular}{|c|c|c|c|c|c|}
\hline Construct & Sub-Constructs & Item & $\begin{array}{c}\text { Factor } \\
\text { Loadings }\end{array}$ & $\begin{array}{c}\text { Reliability after } \\
\text { extraction }\end{array}$ & AVE \\
\hline & \multirow[t]{4}{*}{ New revenue models } & 52 & 0.897 & \multirow[t]{4}{*}{0.837} & \multirow[t]{4}{*}{0.747} \\
\hline & & 53 & 0.831 & & \\
\hline & & 54 & 0.863 & & \\
\hline & & 55 & 0.041 & & \\
\hline & \multirow[t]{4}{*}{ New cost structures } & 56 & 0.864 & \multirow[t]{4}{*}{0.870} & \multirow[t]{4}{*}{0.742} \\
\hline & & 57 & 0.876 & & \\
\hline & & 58 & 0.843 & & \\
\hline & & 59 & 0.317 & & \\
\hline & Total & 33 & & 0.772 & 0.801 \\
\hline Knowledge exploration & & 3 & & 0.871 & - \\
\hline Knowledge exploitative & & 2 & & 0.734 & - \\
\hline \multirow{7}{*}{ Contextual ambidexterity } & \multirow{4}{*}{ Alignment } & 65 & 0.814 & & \\
\hline & & 66 & 0.823 & & \\
\hline & & 67 & 0.811 & & \\
\hline & & 68 & 0.903 & & \\
\hline & \multirow{2}{*}{ Adaptability } & 69 & 0.897 & & \\
\hline & & 70 & 0.883 & & \\
\hline & Total & 6 & - & 0.851 & 0.782 \\
\hline
\end{tabular}

\section{Discussion}

The research work has attempted to empirically answer four identified research gaps of the existing knowledge body. This study has identified the four crucial research gaps of literature. This signifies the contribution of this study that it have attempted to empirically investigate some of hidden underlying elements that shapes the extent of innovation in business model. Researchers argued that the limited empirical researches are available on the operationalization of innovation capabilities and thus, its determinants need to be empirically validated among different cultural contexts (Srivastava \& Shainesh, 2015; Chamsuk, Fongsuwan, \& Takala, 2017). In addition, the review of literature also revealed that the concept of business model innovation has newly emerged and negligible researches have been carried out with quantitative research design (Foss \& Saebi, 2018). This is identified as a gap. In order to address this research gap, the research question one was established. The detailed validity and reliability analysis of the research measures further fill this research gap with the establishment of detailed empirical testing of the operationalization of these measures.

The review of existing literature revealed that innovation capabilities may carry some influential effects on the business model innovation that needs to be empirically investigated. In addition, Teece (2018) also pointed that there is also need to empirically investigate the innovation capabilities in relation to some performance indicator such as service innovation success. 


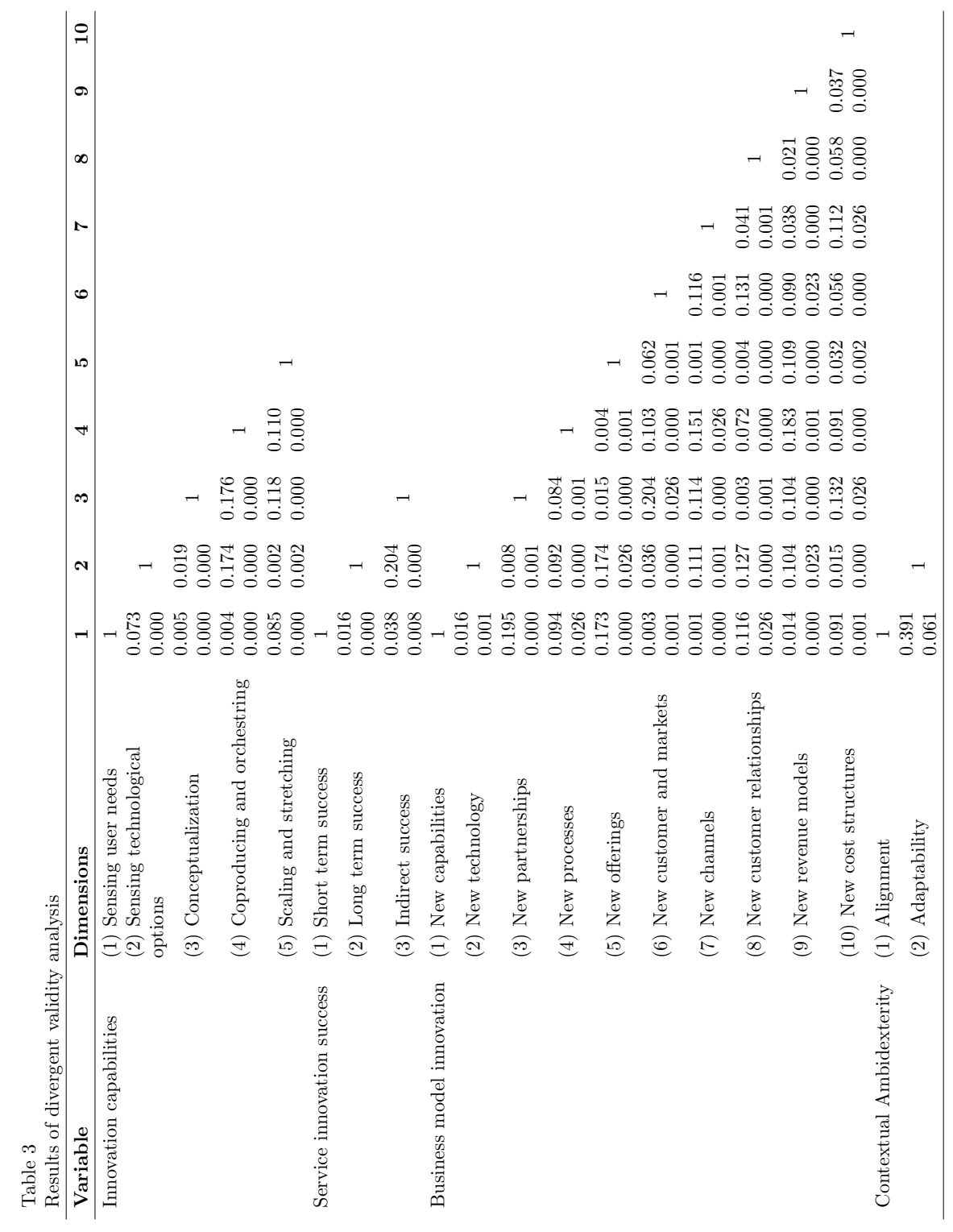


Table 4

Simple regression analysis - H1

\begin{tabular}{lllll}
\hline Variable & Coefficient & S.E & T & P \\
\hline Constant & 1.020 & 0.193 & & \\
Inn Capabilities & 0.473 & 0.039 & 5.120 & 0.000 \\
& $R^{2}=0.460, \mathrm{~F}$ & $(1,343)=26.2, \mathrm{p}=0.000$ \\
\hline
\end{tabular}

Table 5

Testing Proposed Research Model - Regression based conditional process analysis (Hayes, 2017)

\begin{tabular}{lcccccccc}
\hline Antecedent & \multicolumn{3}{c}{ Service Innovation Success } & \multicolumn{3}{c}{ Business Model Innovation } \\
\hline & Coef. & SE & T & P & Coef. & SE & T & P \\
\hline Constant & 1.7890 & 0.535 & 6.450 & 0.000 & 3.548 & 0.647 & 4.41 & 0.000 \\
Innovation capab & 0.4129 & 0.160 & 3.440 & 0.000 & 0.4736 & 0.209 & 13.1 & 0.091 \\
Exploration \& Exploitative & 0.3644 & 0.158 & 2.930 & 0.001 & 0.3016 & 0.208 & 9.68 & 0.000 \\
Contextual Ambidexterity & 0.1911 & 0.112 & 2.710 & 0.000 & 0.2718 & 0.192 & 8.34 & 0.000 \\
Service Innovation & - & - & - & - & 0.2741 & 0.059 & 2.94 & 0.000 \\
Interaction-1 & 0.1998 & 0.045 & 3.210 & 0.000 & - & - & - & - \\
Interaction-2 & 0.2031 & 0.110 & 4.440 & 0.001 & - & - & - & - \\
& & & & $\mathrm{R} 2=0.7137, \mathrm{~F}$ & $(5,339)=46.02, \mathrm{p}=0.000$ \\
\hline
\end{tabular}

Thus, it serves as research gaps. In order to fill these gaps, the research question two, three and the hypothesis one and two were established. The results revealed that service innovation success carries the positive mediation effect among the innovation capabilities and the innovation in business model. This finding is also found to in line with the existing literature that proposed and identified the theoretical logic for the possible relationship (Bashir \& Verma, 2019).

The review of literature also revealed that the role of knowledge exploration and exploitation practices in relation to the innovation capabilities and the its performance outcome in terms of innovation needs to be empirically examined (Peng et al., 2019). In order to close this research gap, the research hypothesis four was established. The results revealed that the knowledge exploration and exploitation both casts the positive moderation effect on the innovation capabilities and success of service innovation. These findings were found to consistent with the existing literature that explains that the organization may enhance the overall efficiency and innovation by searching for new knowledge and then engages itself in utilization of this acquired knowledge (Li \& Huang, 2012; Kang \& Snell, 2009). Another research gap was identified from existing literature that indicated that there is a need to empirically investigate the contextual ambidexterity in relation with the knowledge exploration, exploitative and innovation capabilities. The research hypothesis four and five was established in this regard. The results revealed that the contextual ambidexterity carries a positive moderation effect. This result was also consistent with the existing literature body that explains that the alignment and adaptability of the explored and exploited knowledge is something essential to achieve the success of new value offering services (Kang \& Snell, 2009; Hughes, 2018). 


\section{Conclusion and Recommendations}

The recommendations of this research work is twofold, as it suggests implication for the practitioners of mobile banking sector as well as it provides directions for future scholarly work as;

\section{Implications for Practitioners}

This study suggest some inferences for the mangers of mobile banking sector. The findings of this study refers that the knowledge exploration and knowledge exploitative practices plays an eminent role in bringing the success in newly offered services. The results also refers that it also plays an eminent role in achieving the higher level of innovation in business models. In this regard, it is an essential for the practitioners of mobile banking sector to foster their employees towards knowledge based gatherings i.e. seminars, workshop, symposium organized by academicians or researchers. It is essential for them to gain insight from the informational conferences, summits, formal or informal gathering among market players that may enable them to understand the complex dynamics of market. The findings also revealed that mobile banking sector of Pakistan needs to spend more investment in research and development that would help them in conceptualizing the more innovative product or services or business process. Another important aspect is promotion of experimentation within the organization. The employee need to be encourage for trying, adopting and practicing the new processes or phenomenon or ideas. In addition, the sharing of the knowledge is another crucial element that practitioners of mobile banking sector needs to focus on. Attending and participating the informational gatherings i.e. seminars, symposium, conferences, summits etc. would not help until and unless, the acquired knowledge is shared among the other members. The success as well as the failure stories needs to be discussed across the organizations to foster the facilitative knowledge sharing environment. Another essential aspect for the business model innovation is the dire need to understand the growing needs of potential customer due to well-awareness. This element is again achieved by the effective exploration and exploitation of knowledge by the organization. Lastly, the research instrument of this study also provides an applied technique to assess the extent of the innovative capabilities, knowledge exploration and exploitative practices experience by the organization. These research instrument can help the practitioners of mobile banking sector to study these constructs in their organization in quantitative manner.

\section{Avenues for Future Research}

This research study have studied the role of knowledge exploration and exploitative studies in lieu with the contextual ambidexterity, however the structural ambidexterity have not been considered which serves as the limitation of this study. Future researches are suggested to empirically explore the role of structural ambidexterity and entrepreneurial orientation of the management in regulating the service innovation. Furthermore, this research study has not taken in consideration the behavioral aspects of employees and therefore, suggests 
that the elements of work attitude behavior may also be considered. Future researches can also extend the present model of this study by investigating the effect of this research model on the organizational performance and competitive advantage.

\section{References}

Bashir, M., \& Verma, R. (2019). Internal factors \& consequences of business model innovation. Management Decision, 57(1), 262-290.

Chamsuk, W., Fongsuwan, W., \& Takala, J. (2017). The effects of R\&D and innovation capabilities on the Thai automotive industry part's competitive advantage: A SEM approach. Management and Production Engineering Review, 8(1), 101-112.

Clauss, T. (2017). Measuring business model innovation: Conceptualization, scale development, and proof of performance. RED Management, 47(3), 385-403.

Foss, N. J., \& Saebi, T. (2018). Business models and business model innovation: Between wicked and paradigmatic problems. Long Range Planning, 51(1), 9-21.

Geissdoerfer, M., Vladimirova, D., Fossen, K., \& Evans, S. (2017). Product, service, and business model innovation: A discussion. Procedia Manufacturing, Forthcoming, 21, 165-172.

Gibson, C. B., \& Birkinshaw, J. (2004). The antecedents, consequences, and mediating role of organizational ambidexterity. Academy of Management Journal, 47(2), 209-226.

Gonzalez, R. V. D., \& de Melo, T. M. (2018). The effects of organization context on knowledge exploration and exploitation. Journal of Business Research, 90, 215-225.

Hayes, A. F. (2017). Introduction to mediation, moderation, and conditional process analysis: A regression-based approach. Guilford publications.

Hertog, P. d. (2000). Knowledge-intensive business services as co-producers of innovation. International Journal of Innovation Management, 4(04), 491-528.

Hofstede, G. (2001). Culture's consequences: Comparing values, behaviors, institutions and organizations across nations. Sage publications.

Hossain, M. (2017). Business model innovation: Past research, current debates, and future directions. Journal of Strategy and Management.

Hughes, M. (2018). Organisational ambidexterity and firm performance: Burning research questions for marketing scholars. Journal of Marketing Management, 34(1-2), 178229.

Janssen, M. J., Castaldi, C., \& Alexiev, A. (2016). Dynamic capabilities for service innovation: Conceptualization and measurement. R\&D Management, 46(4), 797811.

Kang, S.-C., \& Snell, S. A. (2009). Intellectual capital architectures and ambidextrous learning: A framework for human resource management. Journal of Management Studies, 46(1), 65-92.

Kiani, M. N., Ahmad, M., \& Gillani, S. H. M. (2019). Service innovation capabilities as the precursor to business model innovation: a conditional process analysis. Asian Journal of Technology Innovation, 27(2), 194-213. 
Kiani, M. N., Mustafa, S. H., \& Ahmad, M. (2019). Does innovation capabilities affect the new service innovation success among pakistani cellular companies? Asia Pacific Journal of Innovation and Entrepreneurship, 13(1), 2-16.

Kim, C. Y., Lim, M. S., \& Yoo, J. W. (2019). Ambidexterity in external knowledge search strategies and innovation performance: Mediating role of balanced innovation and moderating role of absorptive capacity. Sustainability, 11(18), 5111.

Krejcie, R. V., \& Morgan, D. W. (1970). Determining sample size for research activities. Educational and Psychological Measurement, 30(3), 607-610.

Laursen, K., \& Salter, A. (2006). Open for innovation: the role of openness in explaining innovation performance among UK manufacturing firms. Strategic Management Journal, 27(2), 131-150.

Li, Y.-H., \& Huang, J.-W. (2012). Ambidexterity's mediating impact on product development proficiency and new product performance. Industrial Marketing Management, $41(7), 1125-1132$.

Narcizo, R. B., Canen, A. G., \& Tammela, I. (2017). A conceptual framework to represent the theoretical domain of'innovation capability'in organizations. Journal of Entrepreneurship, Management and Innovation, 13(1), 147-166.

Ostrom, A. L., Bitner, M. J., Brown, S. W., Burkhard, K. A., Goul, M., Smith-Daniels, V., .. Rabinovich, E. (2010). Moving forward and making a difference: Research priorities for the science of service. Journal of Service Research, 13(1), 4-36.

Peng, M. Y.-P., Zhang, Z., Yen, H.-Y., \& Yang, S.-M. (2019). Dynamic capabilities and firm performance in the high-tech industry: Quadratic and moderating effects under differing ambidexterity levels. Sustainability, 11(18), 5004.

PTA. (2017). PTA Annual Report 2017. Islamabad: PTA.

PTA. (2018). PTA Annual Report 2018. Islamabad: PTA.

Saebi, T., Lien, L., \& Foss, N. J. (2017). What drives business model adaptation? The impact of opportunities, threats and strategic orientation. Long Range Planning, $50(5), 567-581$.

Schneider, S., \& Spieth, P. (2013). Business model innovation: Towards an integrated future research agenda. International Journal of Innovation Management, 17(1).

Spieth, P., Schneckenberg, D., \& Ricart, J. E. (2014). Business model innovation-state of the art and future challenges for the field. R\&d Management, 44(3), 237-247.

Srivastava, S. C., \& Shainesh, G. (2015). Bridging the service divide through digitally enabled service innovations: Evidence from Indian healthcare service providers. Mis Quarterly, 39(1), 245-267.

Teece, D. J. (2012). Dynamic capabilities: Routines versus entrepreneurial action. Journal of Management Studies, 49(8), 1395-1401.

Teece, D. J. (2018). Business models and dynamic capabilities. Long Range Planning, $51(1), 40-49$.

Trapp, M., Voigt, K.-I., \& Brem, A. (2018). Business models for corporate innovation management: Introduction of a business model innovation tool for established firms. International Journal of Innovation Management, 22(1).

Yamakawa, Y., Yang, H., \& Lin, Z. J. (2011). Exploration versus exploitation in alliance portfolio: Performance implications of organizational, strategic, and environmental 
fit. Research Policy, 40(2), 287-296.

Zawislak, P. A., Cherubini Alves, A., Tello-Gamarra, J., Barbieux, D., \& Reichert, F. M. (2012). Innovation capability: from technology development to transaction capability. Journal of Technology Management \& Innovation, 7(2), 14-27. 